\title{
Differential Effects of Abscisic Acid and Glycine Betaine on Physiological Responses to Drought and Salinity Stress for Two Perennial Grass Species
}

\author{
Zhimin Yang \\ Horticulture College of Nanjing Agricultural University, Nanjing 210095, China
}

Jingjin Yu

School of Soil and Water Conservation, Beijing Forestry University, Beijing 100083, China

\author{
Emily Merewitz and Bingru Huang ${ }^{1}$ \\ Department of Plant Biology and Pathology, Rutgers University, 59 Dudley Road, New Brunswick, NJ \\ 08901
}

\begin{abstract}
AdDitional IndeX words. Agrostis stolonifera, Poa pratensis, plant hormone, osmoregulator, water stress
ABstract. Abscisic acid (ABA) and glycine betaine (GB) may regulate plant responses to drought or salinity stress. The objectives of this controlled-environment study were to determine whether foliar application of ABA or GB improves turf quality under drought or salinity and whether improved stress responses were associated changes in antioxidant metabolism in two C3 turfgrass species, creeping bentgrass (Agrostis stolonifera) and kentucky bluegrass (Poa pratensis). Physiological parameters evaluated included turf quality, leaf relative water content, membrane electrolyte leakage (EL), membrane lipid peroxidation [expressed as malondialdehyde (MDA) content], and activity of superoxide dismutase (SOD), peroxidase (POD), and ascorbate peroxidase (APX). Abscisic acid and GB were both effective in mitigating physiological damage resulting from drought or salinity for both grass species, but effects were more pronounced on kentucky bluegrass. The most notable effects of ABA or GB application were the suppression of EL and MDA accumulation and an increase in APX, POD, and SOD activities after prolonged periods of drought (21 days) or salinity stress (35 days). These results suggest foliar application of ABA or GB may alleviate physiological damage by drought or salinity stress in turfgrass and the maintenance of membrane stability and active antioxidant metabolism could contribute to the positive effects in the stress mitigation effects.
\end{abstract}

Drought and salinity stress are common problems in turfgrass management resulting from limited availability of fresh water for irrigation and increased use of non-potable water sources for irrigation of turfgrasses. Irrigating with water of poor quality can induce osmotic stress and cause physiological injury to plants (Carrow and Duncan, 1998; Pessarakli and Szabolcs, 1999). Internal water deficit is the primary cause of injury during drought or salinity stress as a result of excessive water loss or induced osmotic stress (Nilsen and Orcutt, 1996). The ability to maintain leaf hydration under drought or salinity stress is a highly desirable trait for turfgrasses (Fry and Huang, 2004). Leaf dehydration disrupts various physiological processes and may lead to production of reactive oxygen species (ROS). Buildup of ROS such as ${ }^{1} \mathrm{O}_{2}$ and $\mathrm{H}_{2} \mathrm{O}_{2}$ can cause oxidative damage to cellular membranes and macromolecules (Mittler, 2002). Specific plant defense mechanisms contributing to drought or salinity tolerance include the accumulation of hormones and osmoregulants to govern plant water relations and protect against oxidative damage.

Abscisic acid is a plant hormone that regulates plant response to water deficit by inducing stomatal closure to reduce water loss from leaves (Blackman and Davies, 1985) while also

Received for publication 15 Feb. 2012. Accepted for publication 14 Mar. 2012. We thank the Chinese Scholarship Council for providing a stipend during the study at Rutgers University and also to the Center for Turfgrass Science at Rutgers University for additional research support. Thanks also to David Jespersen and Patrick Burgess at Rutgers University for critical review of the manuscript.

${ }^{1}$ Corresponding author. E-mail: huang@aesop.rutgers.edu. mediating other protective processes such as ROS scavenging (Jiang and Zhang, 2001). It is well known that ABA accumulates in response to drought or salinity stress (Wilkinson and Davies, 2010; Zhang et al., 2006) and that this accumulation promotes stress tolerance in various plant species (Aswath et al., 2005; McCann and Huang, 2008; Qin and Zeevaart, 2002). It was shown that exogenous ABA application enhanced growth and quality of drought-stressed creeping bentgrass, kentucky bluegrass, and tall fescue (Festuca arundinacea) and is associated with a reduction in water loss and increased osmotic adjustment (Jiang and Huang, 2001; McCann and Huang, 2008; Wang et al., 2003). Research on transgenic plants has shown that increased expression of key regulatory genes for ABA biosynthesis and accumulation improved arabidopsis (Arabidopsis thaliana) tolerance to drought stress (Iuchi et al., 2001) and rice (Oryza sativa) tolerance to salinity stress (Moons et al., 1995).

Plants also accumulate various types of compatible organic solutes to enhance drought or salinity tolerance (Bohnert and Jensen, 1996; Serraj and Sinclair, 2002; Yancey et al., 1982). Glycine betaine is an important compatible solute, which accumulates primarily in chloroplasts and has been shown to mitigate abiotic stress by functioning as an osmolyte in osmotic adjustment (Ashraf and Foolad, 2007). Other stress-protective roles of GB include involvement in stress signaling transduction pathways as well as maintenance of thylakoid membrane efficacy for maintaining photosynthesis during environmental stresses (Génard et al., 1991; Robinson and Jones, 1986). It was reported that exogenous application of GB 
or overexpression of GB-synthesizing genes increased endogenous GB content and enhanced plant tolerance to drought or salinity stress for low GB-accumulating or non-accumulating plant species (Agboma et al., 1997; Harinasut et al., 1996; Lutts, 2000; Mäkelä et al., 1998; Yang and Lu, 2005). Endogenous GB accumulation has been positively correlated with drought or salinity tolerance mostly in annual crops (Fallon and Phillips, 1989; McCue and Hanson, 1990; Weimberg et al., 1984; Yang et al., 2003).

Abscisic acid and GB may elicit differential responses of the plant antioxidant system during exposure to drought or salinity stress. Abscisic acid was found to serve in the signal transduction pathway associated with upregulation of antioxidant activity in callus cells of cotton (Gossypium hirsutum) (Bellaire et al., 2000) and increased the activity of antioxidant enzymes in wheat (Triticum aestivum) (Agarwal et al., 2005) and bermudagrass (Cynodon dactylon) (Lu et al., 2008). During drought stress, ABA has been shown to stimulate increased response of the plant antioxidant system by increasing the activity of several antioxidant enzymes in Crocus sativus (Maleki et al., 2011). However, some studies have indicated that the responses of antioxidant enzymes may be variable dependent on duration of drought stress (short term vs. long term). For instance, application of ABA was more effective in conferring short-term drought tolerance for chickling-pea (Lathyrus sativus) seedlings as measured by the degree of lipid peroxidation (Xiong et al., 2006). Glycine betaine has also been reported to scavenge for ROS (Smirnoff and Cumbes, 1989) and protect plants from salinity-induced oxidative stress (Demiral and Türkan, 2004).

The effectiveness of ABA and GB for improving stress tolerance varies with plant species, stress, and application rate. Previous studies have shown positive effects of exogenous ABA application on drought tolerance in two perennial grass species (creeping bentgrass and kentucky bluegrass), which has been attributed to ABA regulation of water relations (McCann and Huang, 2008; Wang et al., 2003). Both compounds may suppress oxidative damages by increasing the activity of different antioxidant enzymes, although little information is available on antioxidant modulation by $\mathrm{ABA}$ or GB in perennial grass species (Lu et al., 2008). In addition, it is not yet clear whether responses of different turfgrass species to ABA or GB vary with the type of stresses such as drought and salinity stress. Little information is available regarding turfgrass response to foliar GB. Such information is pivotal in developing effective chemical products and management strategies to promote turfgrass growth under drought or salinity stress. Therefore, the objectives of this study were to evaluate differential responses of creeping bentgrass and kentucky bluegrass to foliar application of ABA or GB under drought or salinity stress and to examine whether improved stress tolerance was associated with the mitigation of lipid peroxidation and enhancement in the activity of major antioxidant enzymes.

\section{Materials and Methods}

Plant materials. Mature sod pieces $(2-3 \mathrm{~cm}$ thick) of 'Penncross' creeping bentgrass and 'Baron' kentucky bluegrass were transplanted into polyvinyl chloride (PVC) tubes $(10 \mathrm{~cm}$ diameter, $40 \mathrm{~cm}$ long) filled with sand and loam soil $(1: 1 \mathrm{v} / \mathrm{v}$ fine-loamy-mixed mesic Typic Hapludult) on 15 May 2011. Plants were maintained for $50 \mathrm{~d}$ in a greenhouse in New
Brunswick, NJ, with an average temperature of $22 / 16^{\circ} \mathrm{C}$ (day/ night) and 12- to 13-h photoperiod of natural sunlight supplemented with sodium lamps and then moved to a walk-in growth chamber for subsequent treatments. The growth chamber $(3 \times$ $2.5 \mathrm{~m}$ ) was set at $23 / 18^{\circ} \mathrm{C}$ (day/night), a $12-\mathrm{h}$ photoperiod with a photosynthetically active radiation level of $550 \mathrm{mmol} \cdot \mathrm{m}^{-2} \cdot \mathrm{s}^{-1}$ at the turfgrass canopy level. Before stress imposition, plants were watered three times per week until drainage appeared and were fertilized weekly with $100 \mathrm{~mL}$ of soluble $20 \mathrm{~N}-8.8 \mathrm{P}-16.6 \mathrm{~K}$ including micronutrients [0.05\% magnesium, $0.0068 \%$ boron, $0.0036 \%$ copper, $0.05 \%$ iron, $0.025 \%$ manganese, $0.0009 \%$ molybdenum, 0.0025\% zinc (Peter's General Purpose 20-20-20; Grace-Sierra Horticultural Products, Milpitas, CA)] at a concentration of $5 \mathrm{~g} \cdot \mathrm{L}^{-1}$.

Treatment and experimental Design. The experiment consisted of three watering treatments (well-watered control, drought, and salinity) each lasting for $35 \mathrm{~d}$; well-watered controls were irrigated three times per week with tap water to maintain soil volumetric water content $(25 \%)$ at field capacity. To impose drought stress, irrigation was withheld allowing gradual drydown of the soil. To prevent initial salinity shock, the soil in each pot was drenched with $100 \mathrm{~mL} \mathrm{NaCl}$ solution at incremental electrical conductivity (EC) by $3 \mathrm{dS} \cdot \mathrm{m}^{-1}$ per day until the final EC reached $9 \mathrm{dS} \cdot \mathrm{m}^{-1}$. Plants were then irrigated daily with $100 \mathrm{~mL}$ of $9 \mathrm{dS} \cdot \mathrm{m}^{-1} \mathrm{NaCl}$ solution. Leachate was collected at the end of the experiment ( $35 \mathrm{~d}$ of treatment) to verify salinity build-up in soil.

Two foliar treatments of ABA and GB were applied to the plants $3 \mathrm{~d}$ before the imposition of well-watered, drought, or salinity treatments and then weekly during the three water treatments. For ABA treatment, plants in each PVC tube were sprayed with $20 \mathrm{~mL}$ of $100 \mu \mathrm{M}$ ABA solution (Sigma-Aldrich, St. Louis, MO) until the turfgrass canopy was saturated and some dripping occurred. This application rate of ABA was previously found to be effective in promoting drought tolerance in kentucky bluegrass (Wang et al., 2003) and creeping bentgrass (McCann and Huang, 2008). For GB treatment, a preliminary test using different concentrations $(25,50,100$, and $200 \mathrm{~mm})$ of GB (Sigma-Aldrich) was performed to determine optimal dosage amounts for improving plant growth during drought or salinity stress (data not shown). The 100-mm GB solution was found to be the most effective for both species and was therefore used in the present study. Similar to ABA treatment, $20 \mathrm{~mL}$ of $100 \mathrm{~mm}$ GB was sprayed until the turf canopy was completely saturated. Untreated control plants received the same volume of water as in the ABA or GB treatments.

Treatments were arranged as a split-plot design with water treatments as main plots and chemical treatments as subplots. Each water and chemical treatment had four replicates. All pots were randomized within the growth chamber. Statistical significance was tested using the analysis of variance procedure in SAS (Version 9.0; SAS Institute, Cary, NC). Differences between treatments were separated by Fisher's protected least significance difference test at the $0.05 P$ level.

Physiological measurements and anitoxodant analysis. All physiological measurements were made on weekly intervals during the treatments and antioxidant enzyme activities were measured at the end of drought or salinity treatment.

Visual turf quality (TQ) was rated on a scale of 1 to 9 with 1 being completely desiccated and brown turf canopy and 9 representing healthy plants with dark-green turgid leaves and a dense turf canopy (Turgeon, 1996). A rating of 6 was considered the minimal acceptable TQ level. 
Water status of soil and plants was evaluated as soil volumetric water content (SWC) and leaf relative water content (RWC), respectively. SWC was measured by the time domain reflectometry method (Soilmoisture Equipment, Santa Barbara, CA) using a $20-\mathrm{cm}$ probe inserted in the soil (Topp et al., 1980). Leaf RWC was calculated using the formula: $100 \times[(\mathrm{FW}-$ $\mathrm{DW}) /(\mathrm{TW}-\mathrm{DW})]$ where FW is leaf fresh weight immediately after harvesting, TW is leaf turgid weight after soaking in deionized water for $24 \mathrm{~h}$, and DW is leaf dry weight following oven-drying for $72 \mathrm{~h}$ at $80^{\circ} \mathrm{C}$.

Leaf cellular membrane stability was evaluated by measuring electrolyte leakage of leaves (Blum and Ebercon, 1981). Fresh leaves $(0.1-0.2 \mathrm{~g})$ were collected, rinsed, and immersed in $20 \mathrm{~mL}$ deionized water and placed on a conical shaker at $23^{\circ} \mathrm{C}$ for $24 \mathrm{~h}$. The initial conductivity of the solution $\left(\mathrm{C}_{\text {initial }}\right)$ was then measured using a conductivity meter (YSI Inc., Yellow Springs, OH). Leaves were then killed by autoclaving at $140{ }^{\circ} \mathrm{C}$ for $20 \mathrm{~min}$ and placed back on the shaker for $12 \mathrm{~h}$. The final conductivity of killed tissues $\left(\mathrm{C}_{\max }\right)$ was then measured and electrolyte leakage (EL) calculated as the percentage of $\mathrm{C}_{\text {initial }}$ over $\mathrm{C}_{\max }$ (Blum and Ebercon, 1981).

Antioxidant enzyme activity was determined using the method described by Zhang and Kirkham (1996). A $0.40 \mathrm{~g}$ of fresh leaf tissue was ground to a fine powder using a mortar and pestle and extracted with $5 \mathrm{~mL}$ extraction buffer $(50 \mathrm{~mm}$ potassium phosphate, $1 \mathrm{~mm}$ ethylenediaminetetraacetic acid, 1\% polyvinylpyrrolidone, $1 \mathrm{~mm}$ dithiothreitol, $1 \mathrm{~mm}$ phenylmethylsulfonyl, pH 7.8). Extractions were centrifuged at $15,000 g_{\mathrm{n}}$ for $30 \mathrm{~min}$ at $4{ }^{\circ} \mathrm{C}$ and supernatant collected for subsequent enzyme assay and the quantification of malondialdehyde. Superoxide dismutase (EC 1.15.1.1) activity was determined by recording the rate of p-nitro blue tetrazolium chloride reduction at $560 \mathrm{~nm}$ (Giannopolities and Rise, 1977). The activity of peroxidase (EC 1.11.1.7) and ascorbate peroxidase (EC 1.11.1.1) was determined by measuring the changes in absorbance at 470 and 290 $\mathrm{nm}$, respectively. Protein content was determined using Bradford's (1976) method.

Lipid peroxidation was quantified based on MDA content using the method of Dhindsa et al. (1981) with modifications. A $0.8-\mathrm{mL}$ aliquot of supernatant was mixed with $1.6 \mathrm{~mL} 20 \%$ trichloroacetic acid containing $0.5 \%$ thiobarbituric acid. The mixture was heated at $95{ }^{\circ} \mathrm{C}$ for $30 \mathrm{~min}$, quickly cooled on ice, and then centrifuged at $10,000 \mathrm{~g}_{\mathrm{n}}$ for $10 \mathrm{~min}$. The absorbance of the supernatant was read at 532 and $600 \mathrm{~nm}$. The concentration of MDA was calculated using an extinction coefficient of 155 $\mathrm{mM}^{-1} \cdot \mathrm{m}^{-1}$ (Health and Packer, 1968).

\section{Results}

SOIL WATER CONTENT AND ELECTRICAL CONDUCTIVITY LEVELS. Well-watered plants of both species maintained an average 15\% to $20 \%$ SWC during the study (Figs. $1 \mathrm{~A}$ and $2 \mathrm{~A}$ ). Soil water content declined to $4 \%$ to $5 \%$ in both grass species by the end of the drought treatment $(21 \mathrm{~d})$ (Figs. $1 \mathrm{~B}$ and $2 \mathrm{~B}$ ). The salinity treatment maintained SWC at $\approx 20 \%$ and remained stable during the experimental period (Figs. $1 \mathrm{C}$ and $2 \mathrm{C}$ ). The EC of leachate from the soil averaged $13.10 \mathrm{dS} \cdot \mathrm{m}^{-1}$ in the salinity treatment and $2.48 \mathrm{dS} \cdot \mathrm{m}^{-1}$ in the well-watered control treatment.

TURF QUALITY. Regardless of chemical treatments, TQ of both species was maintained at a high level under well-watered conditions (Figs. 3A and 4A). Both drought and salinity treatments caused a significant decline in TQ for the untreated controls
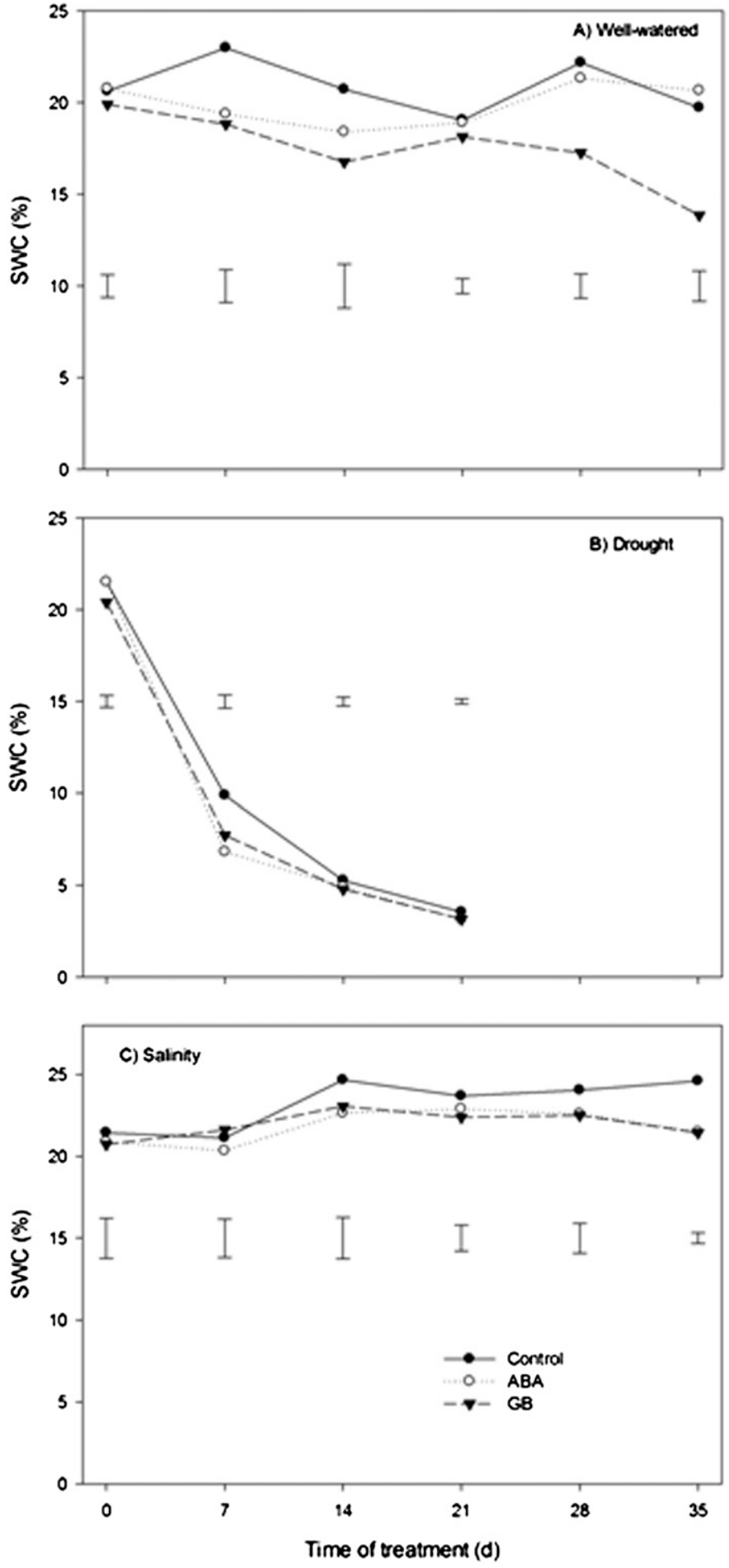

Fig. 1. Soil water content (SWC) of creeping bentgrass 'Penncross' treated with water (control), abscisic acid (ABA), or glycine betaine (GB) under (A) wellwatered conditions, (B) drought stress, and (C) salinity stress. Least significant difference (LSD) bars indicate significant differences between chemical spray treatments within a given day of treatment $(P \leq 0.05)$.

at 14 and $28 \mathrm{~d}$ of stress (Figs. 3B-3C and 4B-C). During drought stress, TQ of creeping bentgrass treated with ABA was significantly higher than the untreated control plants, whereas GB had no significant effects on TQ (Fig. 3B). Creeping bentgrass treated with either ABA or GB had significantly 

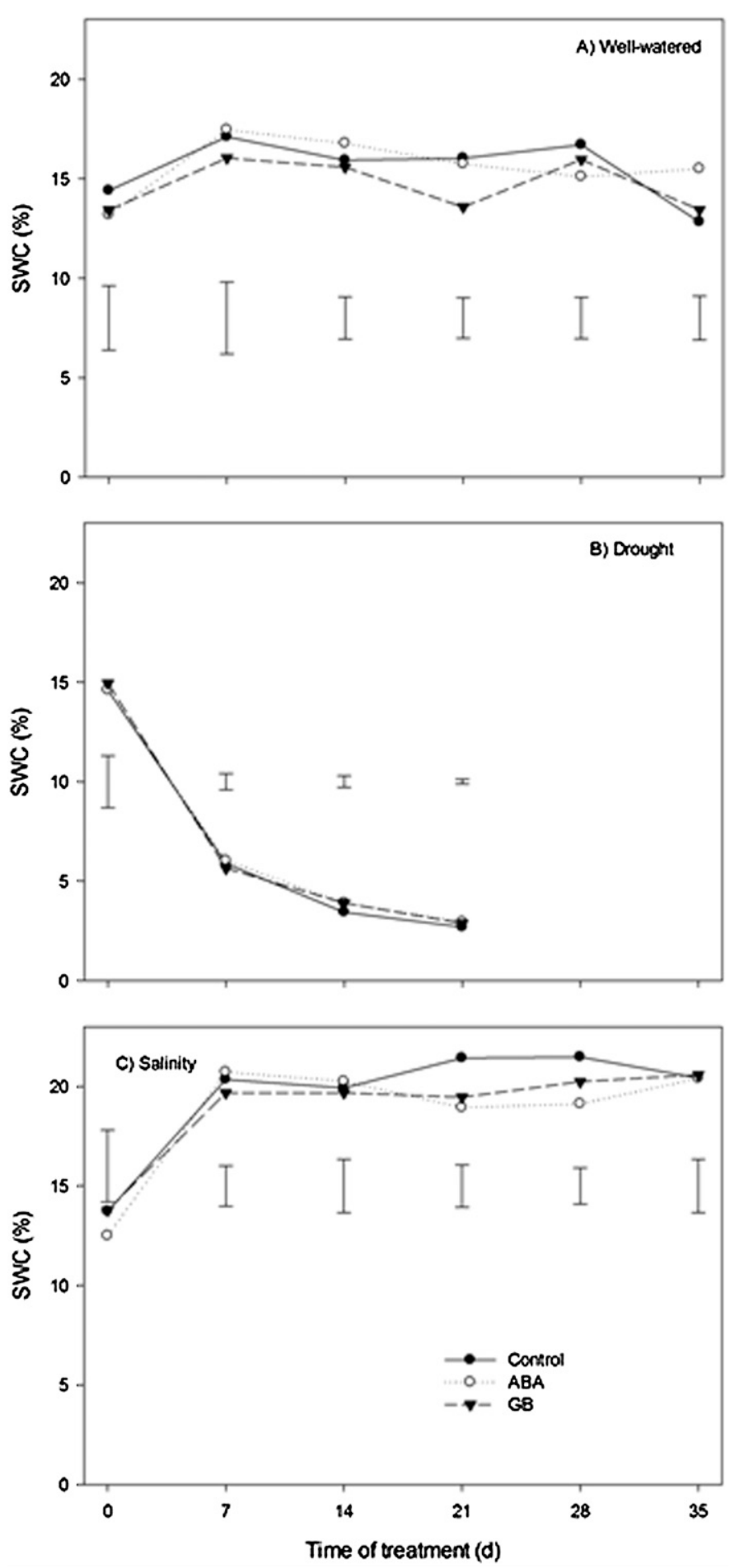

Fig. 2. Soil water content (SWC) of kentucky bluegrass 'Baron' treated with water (control), abscisic acid (ABA), or glycine betaine (GB) under (A) wellwatered condition, $(\mathbf{B})$ drought stress, and (C) salinity stress. Least significant difference (LSD) bars indicate significant differences between chemical spray treatments within a given day of treatment $(P \leq 0.05)$.

higher TQ than the untreated control after $28 \mathrm{~d}$ of salinity stress (Fig. 3C). Kentucky bluegrass TQ was unaffected by ABA or GB treatment under well-watered conditions (Fig. 4A) but both chemicals yielded significantly higher TQ compared with untreated controls at $21 \mathrm{~d}$ of drought (Fig. 4B) and at $28 \mathrm{~d}$ of salinity stress (Fig. 4C).
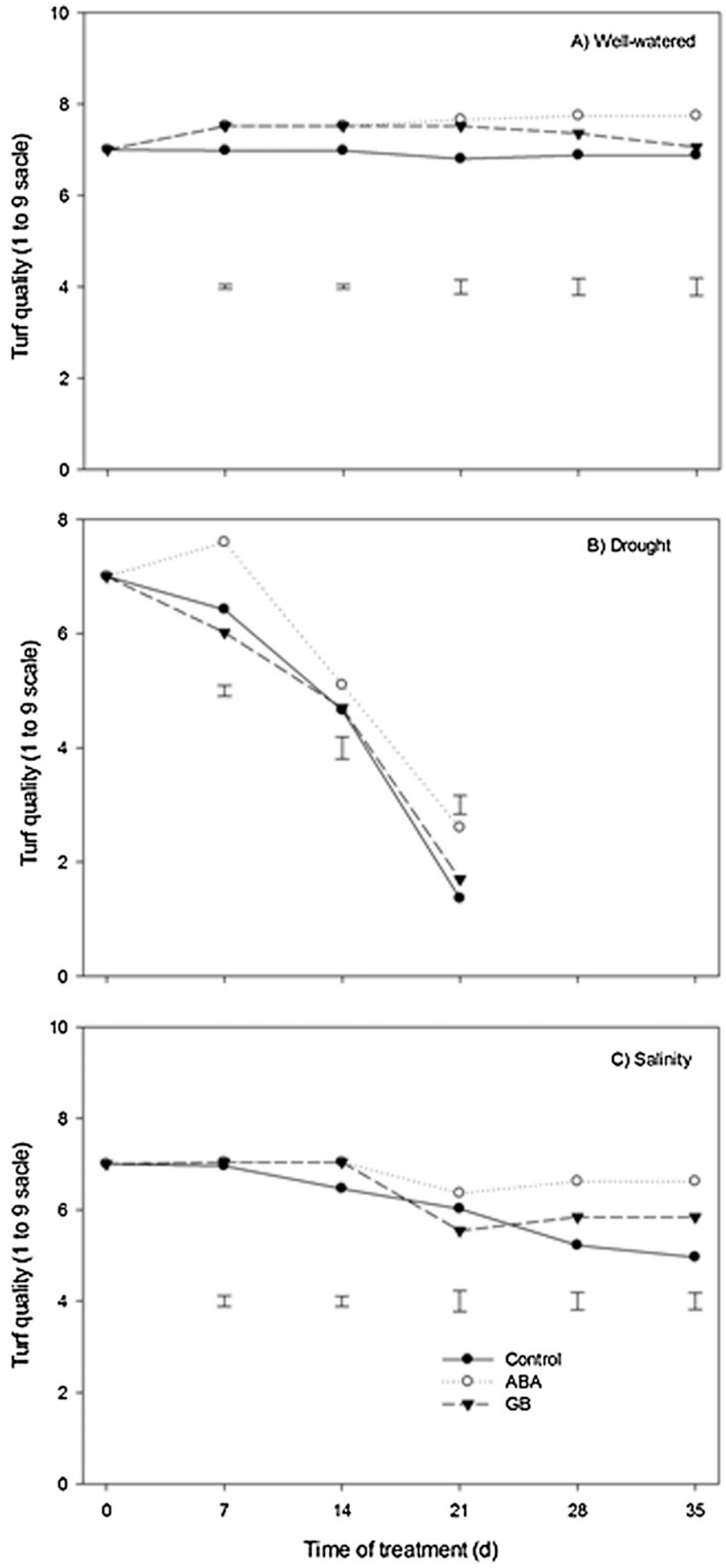

Fig. 3. Turf quality (TQ) of creeping bentgrass 'Penncross' treated with water (control), abscisic acid (ABA), or glycine betaine (GB) as determined by a visual rating $(1=$ desiccated, brown; $9=$ healthy green turf $)$. TQ ratings were determined under (A) well-watered conditions, (B) drought stress, and (C) salinity stress. Least significant difference (LSD) bars indicate significant differences between chemical spray treatments within a given day of treatment $(P \leq 0.05)$.

RELATIVE WATER CONTENT. Leaf RWC of creeping bentgrass was maintained at $\approx 90 \%$ under well-watered conditions (Fig. $5 \mathrm{~A}$ ) and declined rapidly to $28 \%$ by $21 \mathrm{~d}$ of drought stress (Fig. 5B). Salinity treatment caused only a slight decline in leaf RWC 

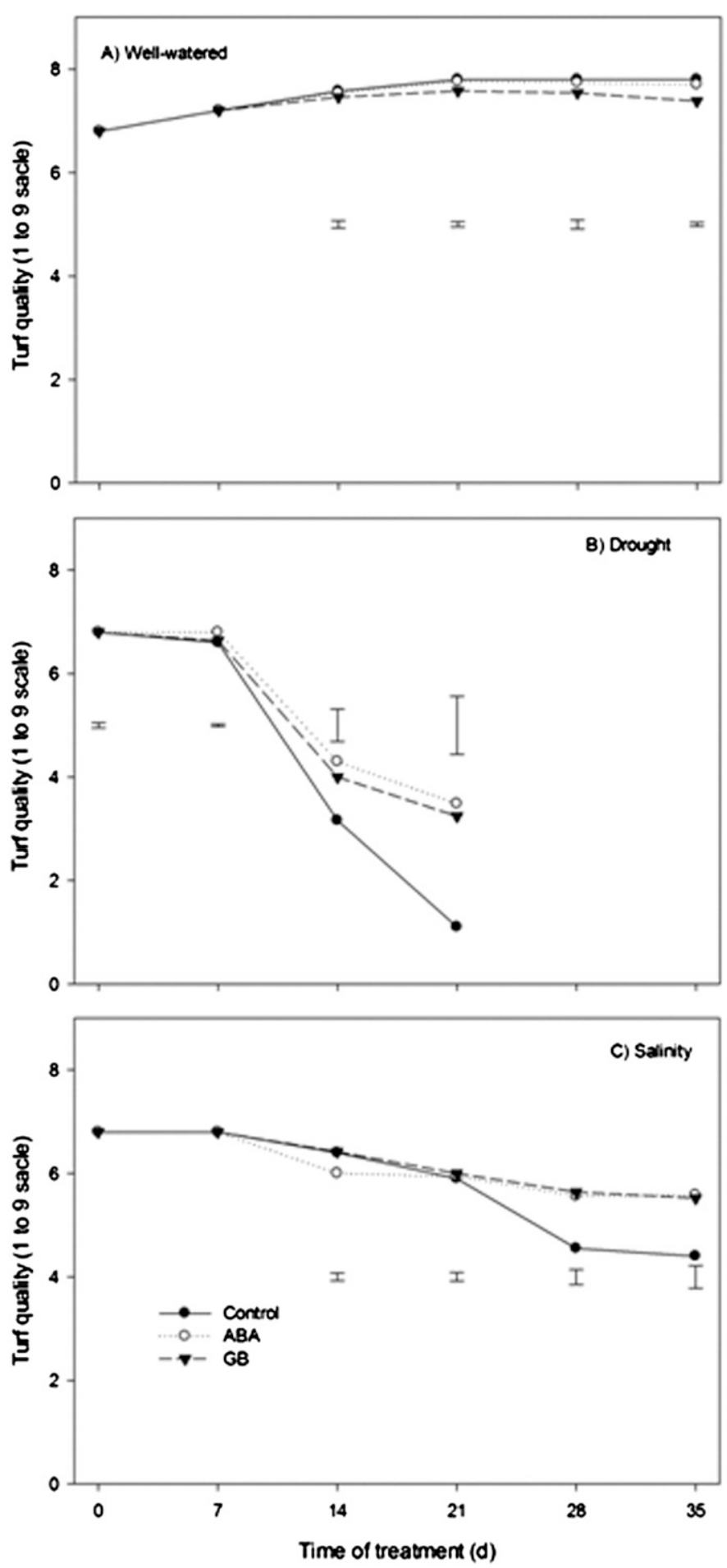

Fig. 4. Turf quality (TQ) of kentucky bluegrass 'Baron' treated with water (control), abscisic acid (ABA), or glycine betaine (GB) as determined by a visual rating $(1=$ desiccated, brown; $9=$ healthy green turf $)$. TQ ratings were determined under (A) well-watered conditions, (B) drought stress, and (C) salinity stress. Least significant difference (LSD) bars indicate significant differences between chemical spray treatments within a given day of treatment $(P \leq 0.05)$.

to $83 \%$ during the experimental period (Fig. 5C). No significant differences in leaf RWC were detected among treatments maintained under well-watered (Fig. 5A) or salinity conditions (Fig. 5C). The RWC of creeping bentgrass treated with ABA or
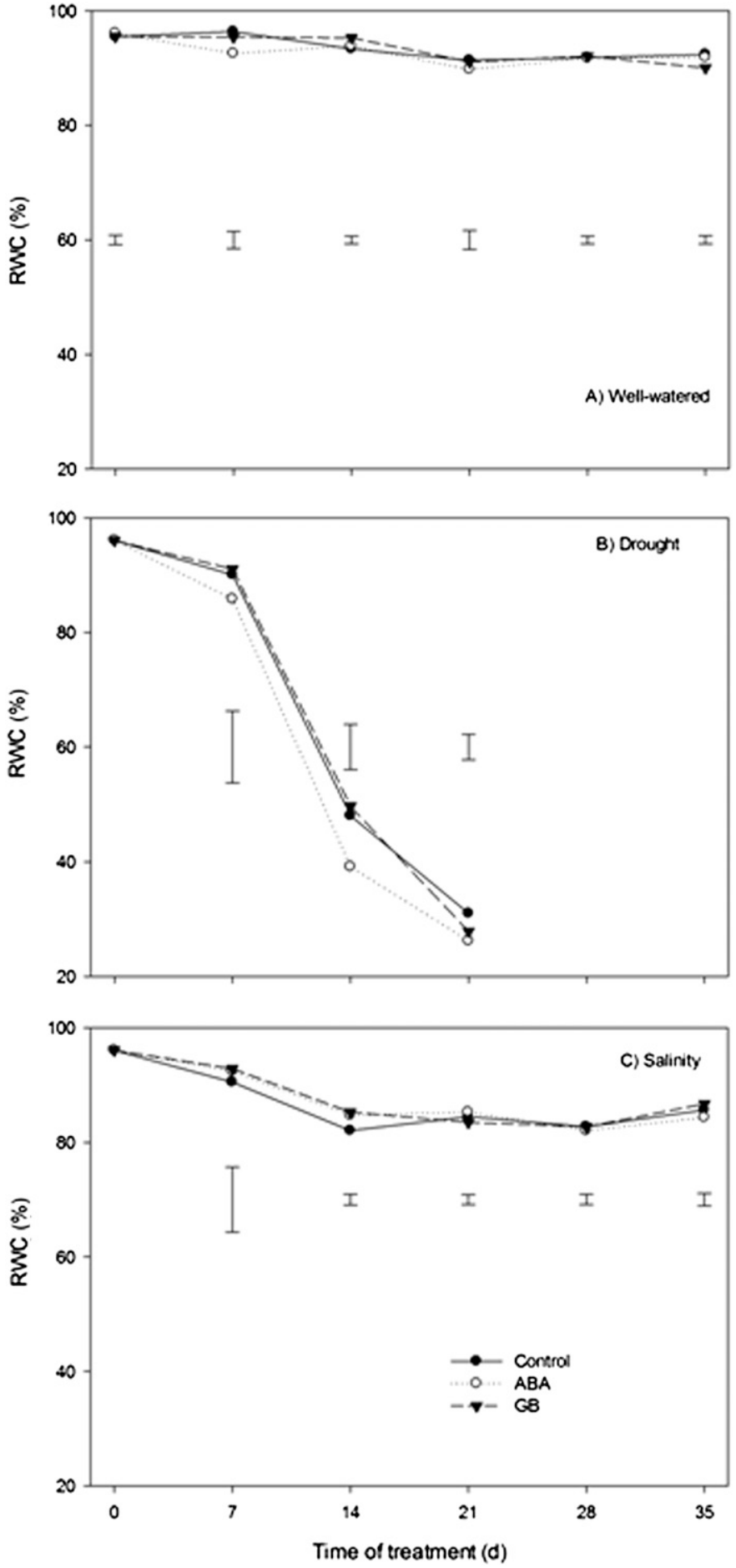

Fig. 5. Leaf relative water content (RWC) of creeping bentgrass 'Penncross' treated with water (control), abscisic acid (ABA), or glycine betaine (GB) under (A) well-watered conditions, (B) drought stress, and (C) salinity stress. Least significant difference (LSD) bars indicate significant differences between chemical spray treatments within a given day of treatment $(P \leq 0.05)$.

GB did not differ from that of the untreated control during most of the experimental period (Fig. 5B).

Neither ABA nor GB treatment had significant effects on kentucky bluegrass RWC under well-watered conditions (Fig. 6A). However, GB was able to maintain significantly greater RWC than the untreated control at $21 \mathrm{~d}$ of drought stress (Fig. 

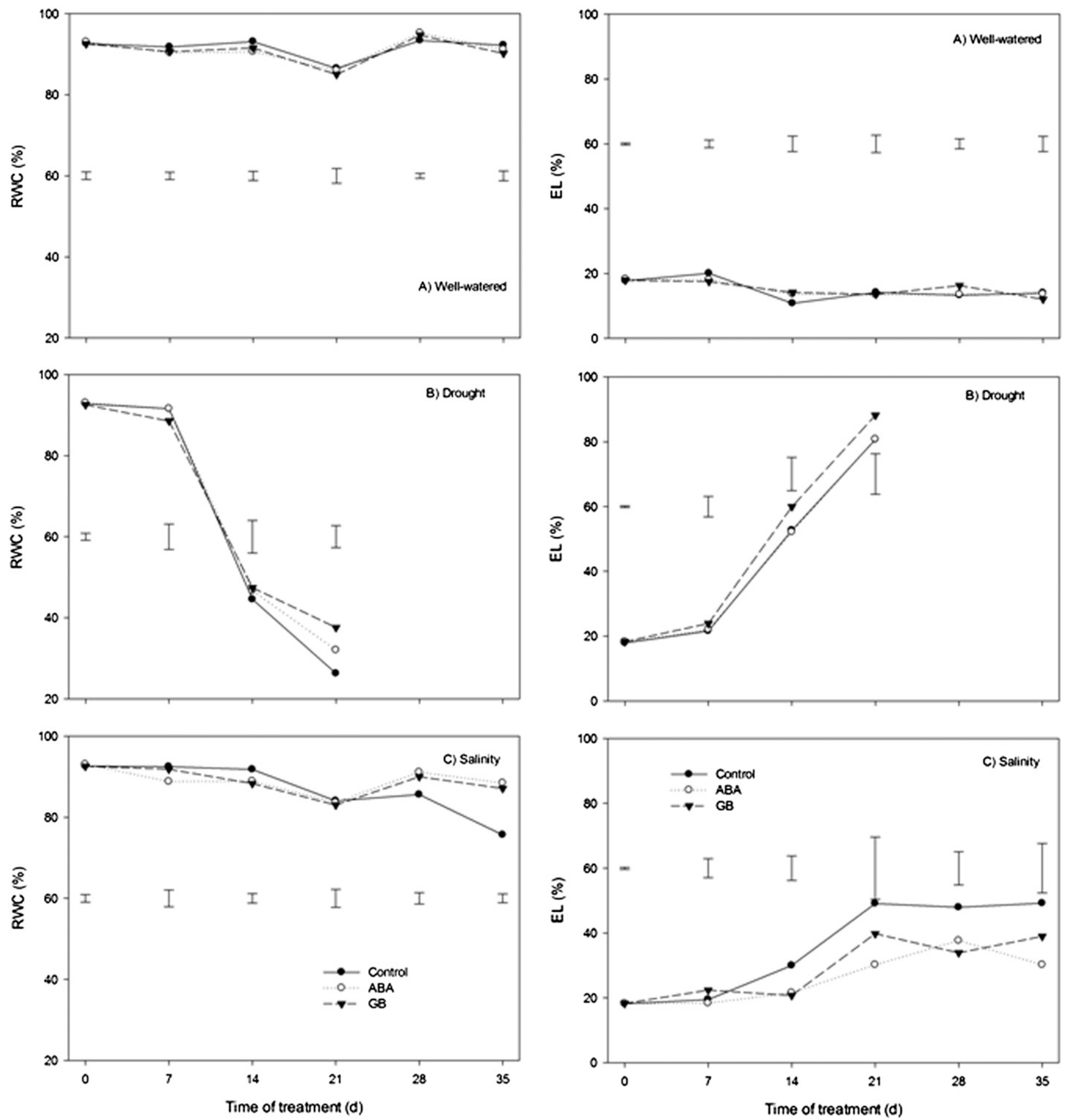

Fig. 6. Leaf relative water content (RWC) of kentucky bluegrass 'Baron' treated with water (control), abscisic acid (ABA), or glycine betaine (GB) under (A) well-watered conditions, (B) drought stress, and (C) salinity stress. Least significant difference (LSD) bars indicate significant differences between chemical spray treatments within a given day of treatment $(P \leq 0.05)$.

6B). After $28 \mathrm{~d}$ of salinity stress, both ABA- and GB-treated kentucky bluegrass had significantly higher leaf RWC than untreated controls (Fig. 6C).

Cellular membrane stability. Leaf EL increased during drought or salinity stress in both species (Figs. 7 and 8). Leaf

Fig. 7. Leaf electrolyte leakage (EL) of creeping bentgrass 'Penncross' indicating loss of cellular membrane stability in response to (A) well-watered conditions, (B) drought stress, and (C) salinity stress. Plants were treated with water (control), abscisic acid (ABA), or glycine betaine (GB). Least significant difference (LSD) bars indicate significant differences between chemical spray treatments within a given day of treatment $(P \leq 0.05)$.

EL was unaffected by ABA or GB treatment under wellwatered conditions (Figs. 7A and 8A). Neither chemical treatment had significant effects on EL under drought stress for creeping bentgrass although ABA-treated kentucky 

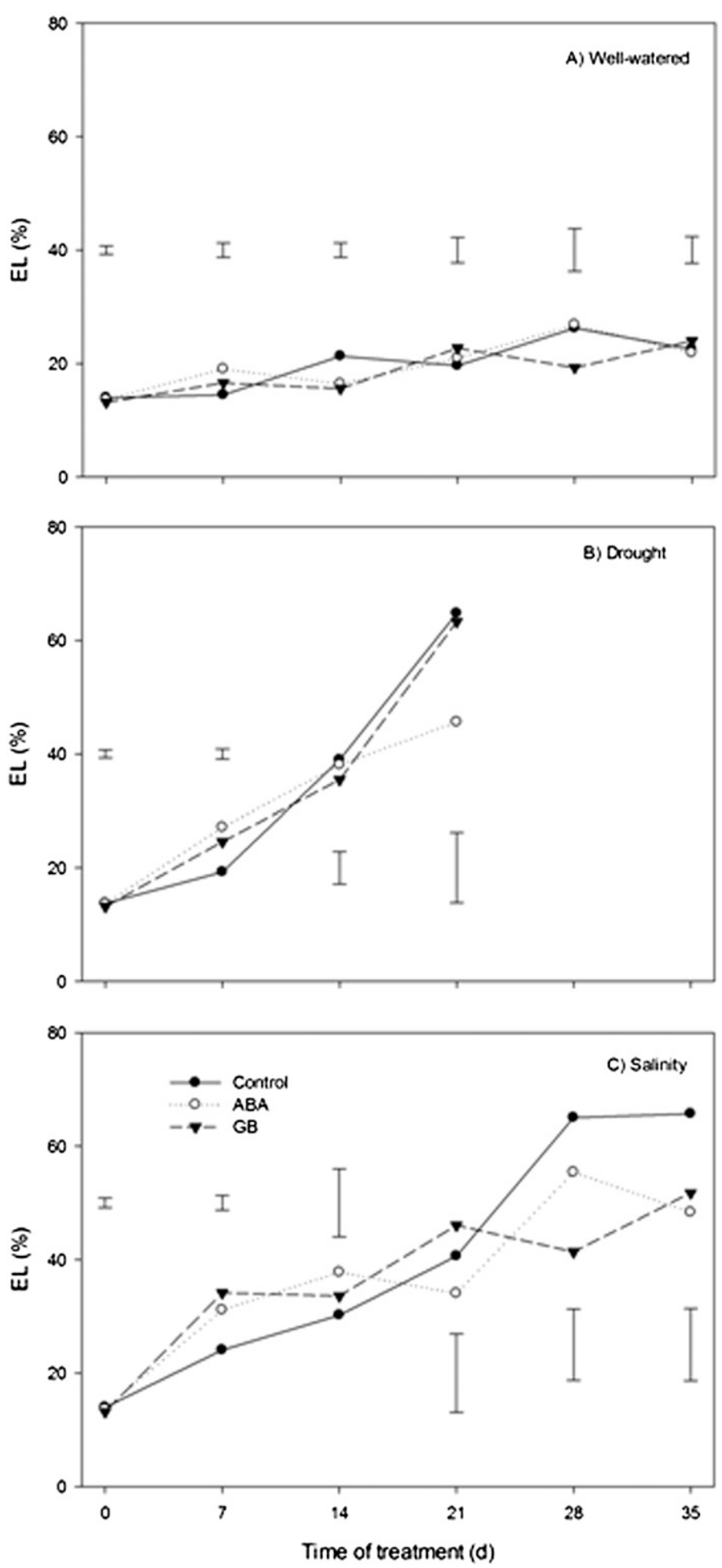

Fig. 8. Leaf electrolyte leakage (EL) of kentucky bluegrass 'Baron' indicating loss of cellular membrane stability in response to $(\mathbf{A})$ well-watered conditions, (B) drought stress, and (C) salinity stress. Plants were treated with water (control), abscisic acid (ABA), or glycine betaine (GB). Least significant difference (LSD) bars indicate significant differences between chemical spray treatments within a given day of treatment $(P \leq 0.05)$.

bluegrass had significantly lower EL at $21 \mathrm{~d}$ of drought stress (Figs. 7B and 8B). Both ABA- and GB-treated plants exhibited lower EL by $28 \mathrm{~d}$ of salinity stress in creeping bentgrass ( $32 \%$ and $24 \%$, respectively) (Fig. 7C) and by $35 \mathrm{~d}$ in kentucky bluegrass ( $21 \%$ and $29 \%$, respectively) (Fig. $8 \mathrm{C}$ ).
LIPID PEROXIDATION AND ANTIOXIDANT ENZYME ACTIVITY. Drought for $21 \mathrm{~d}$ or salinity stress for $35 \mathrm{~d}$ caused significant increases in leaf MDA content relative to the well-watered control plants for both turfgrass species (Fig. 9A-B). Increased MDA content was more apparent in plants exposed to drought stress than salt stress, particularly for creeping bentgrass. Both $\mathrm{ABA}$ and GB treatments reduced MDA content of both species relative to the untreated control treatments under drought or salinity stress. The reduction in MDA was to a greater extent in kentucky bluegrass than creeping bentgrass under drought or salinity stress (Fig. 9A-B).

The activity of SOD in untreated control plants decreased significantly below the well-watered control plants at $21 \mathrm{~d}$ of drought stress in both species and at $35 \mathrm{~d}$ of salinity in creeping bentgrass (Fig. 10A-B). ABA-treated creeping bentgrass had significantly higher SOD activity than the untreated control under all well-watered, drought, or salinity conditions. The application of GB also resulted in higher SOD activities in creeping bentgrass than the untreated control plants under wellwatered or salinity stress but not under drought conditions (Fig. 10A). Neither ABA nor GB treatment had significant effects on SOD activity of kentucky bluegrass maintained under wellwatered conditions but caused significant increases in SOD activity under drought or salinity stress (Fig. 10B).

The activity of APX was reduced by either drought or salinity stress in the untreated control plants in both grass species (Fig. 11A-B). In creeping bentgrass, application of ABA resulted in higher APX activities under well-watered, drought, or salinity conditions, whereas GB treatment caused greater APX activity under drought or salinity stress but not under well-watered conditions. For kentucky bluegrass, neither ABA nor GB had effects on APX under well-watered conditions, but both increased APX activity under drought or salinity stress (Fig. 11B).

The activity of POD declined significantly under drought or salinity stress in the untreated control treatments of both grass species (Fig. 12A-B). Compared with the untreated control plants, POD activity was significantly elevated by ABA and GB treatment under well-watered, drought, or salinity conditions in both grass species (Fig. 12A-B).

\section{Discussion}

The physiological data suggest that ABA treatment enhanced drought tolerance in both turfgrass species but was more effective for kentucky bluegrass. Similar effects have also been reported by McCann and Huang (2008) who found increased TQ scores, growth rate, and leaf photochemical efficiency for ABA-treated creeping bentgrass and kentucky bluegrass compared with untreated controls. The positive effects of ABA on drought tolerance of creeping bentgrass and kentucky bluegrass have been attributed to the induction of stomatal closure lessening water loss and also with enhanced osmotic adjustment maintaining cellular turgidity (McCann and Huang, 2008; Wang et al., 2003). In the present study, foliar ABA significantly reduced EL in kentucky bluegrass plants but did not have significant effects on RWC in either grass species. The application of ABA was found to reduce membrane damages induced by drought stress in other plant species (Rajasekaran and Blake, 1999). Wang et al. (2003) also observed reduced EL and limited effects of ABA on leaf water status for droughtstressed kentucky bluegrass. It is possible that ABA may 

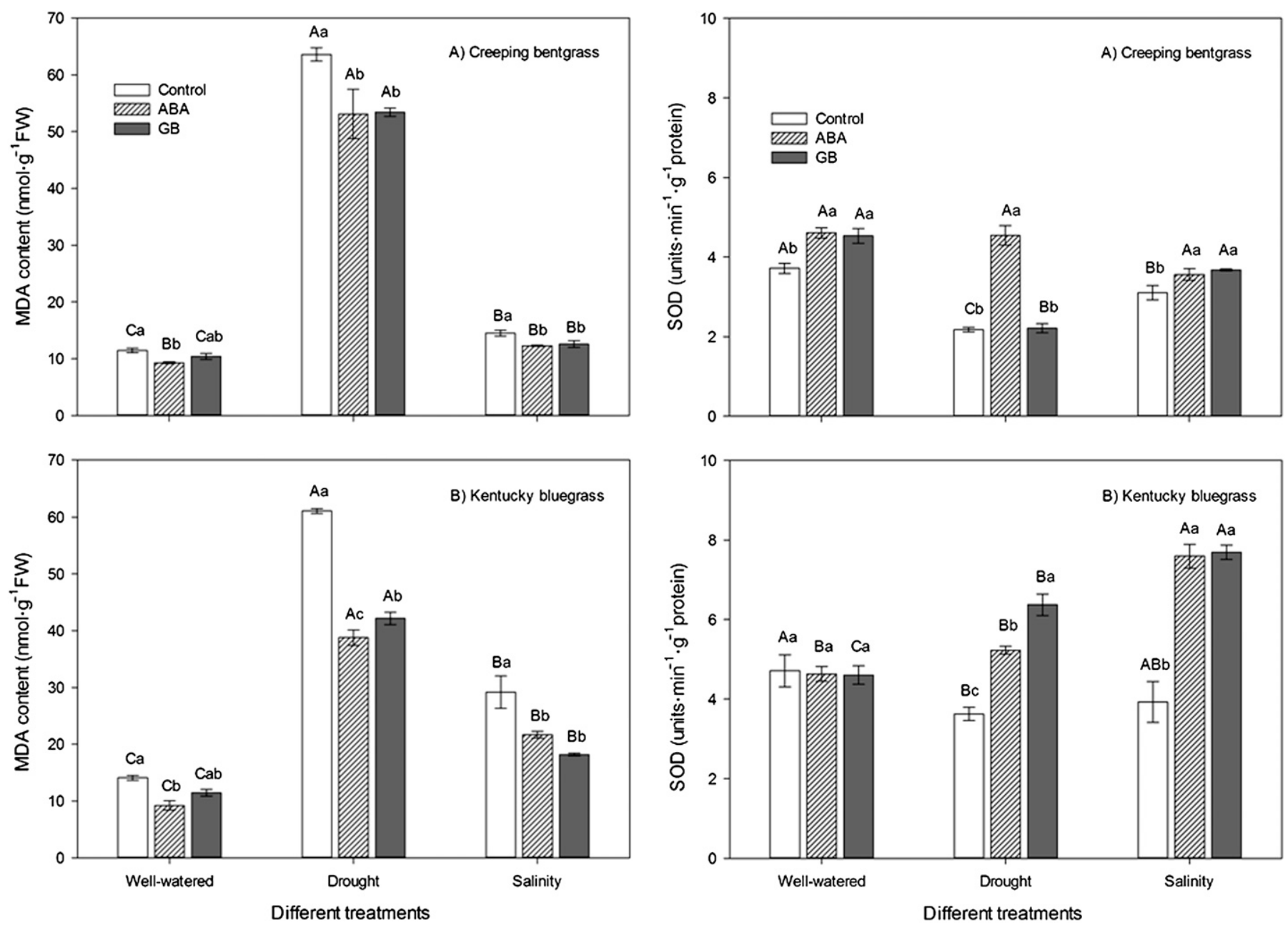

Fig. 9. Leaf malondialdehyde (MDA) content indicating the amount of lipid peroxidation in response to $21 \mathrm{~d}$ of drought and $35 \mathrm{~d}$ of salinity stress for (A) creeping bentgrass 'Penncross' and (B) kentucky bluegrass 'Baron'. Bars marked with lowercase letters are for comparison between untreated control, abscisic acid (ABA), and glycine betaine (GB) treatment under well-watered, drought, or salinity conditions. Bars marked with uppercase letter are for comparison between well-watered, drought-stressed, and salinity-stressed plants under untreated control, ABA treatment, and GB treatment. Different letters indicate significant differences based on least significant difference (LSD) test $(P \leq 0.05)$.

Fig. 10. Activity of the antioxidant enzyme superoxide dismutase (SOD) in (A) creeping bentgrass 'Penncross' and (B) kentucky bluegrass 'Baron' in response to $21 \mathrm{~d}$ of drought and $35 \mathrm{~d}$ of salinity stress. Bars marked with lowercase letters are for comparison among untreated control, abscisic acid (ABA), and glycine betaine (GB) treatment under well-watered, drought, or salinity conditions. Bars marked with uppercase letter are for comparison among well-watered, drought-stressed, and salinity-stressed plants under untreated control, ABA treatment, and GB treatment. Different letters indicate significant differences based on least significant difference (LSD) test $(P \leq$ $0.05)$.

mitigate cellular damage during drought stress without causing changes in whole-plant water relations. The enhancement in stress protection of ABA may be at least partially related to changes in antioxidant metabolism, as discussed subsequently, although various other mechanisms could be involved (Blackman and Davies, 1985; Jiang and Zhang, 2001).

This study found that ABA treatment enhanced TQ and reduced EL during plant exposure to salinity stress for both grass species. To our knowledge, this is the first report of positive effects of $\mathrm{ABA}$ on turfgrass responses to salinity. However, the specific ways in which ABA may promote salinity tolerance are far less understood compared with drought tolerance not only in perennial grass, but also in other plant species in general (Zhang et al., 2006). ABA has been associated with the reduction of chloride accumulation (Gómez-Cadenas et al., 2003) and lessened membrane damage (Rajasekaran and Blake, 1999) as well as improved mineral

nutrition in other plant species (Gadallah, 1996). Salinity stress is complex in that plants will incur cellular damage such as ion imbalance and salt accumulation in addition to changes in plant water status. Little is currently known regarding the protective role of ABA against ionic cellular damage. Salt-tolerant plants tend to accumulate osmolytes, which combat ionic stress by promoting ABA-responsive protective proteins (Skriver and Mundy, 1990) such as late-embryogenesis abundant proteins to mitigate dehydration damages (Moons et al., 1995). Various elements of ABA-responsive genes were found to improve salinity tolerance in rice (Mukherjee et al., 2006) and arabidopsis (Lee et al., 2004). ABA-responsive factors such as the osmolyte accumulation and protective protein generation could be expressed before onset of water deficit and therefore avoid damage by osmotic imbalance.

Effects of foliar GB or genetic control of endogenous GB promoting drought or salinity tolerance are widely recognized 

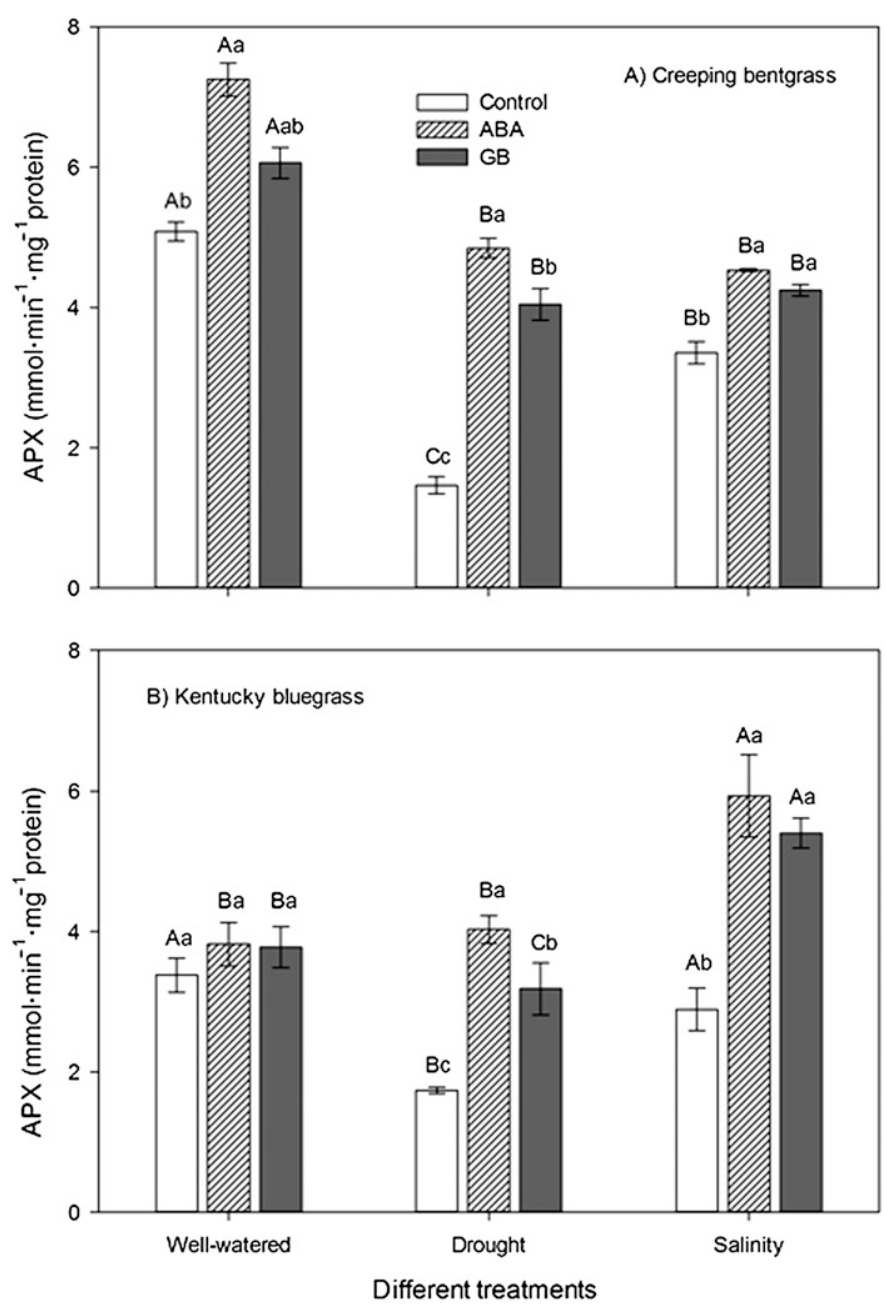

Fig. 11. Activity of the antioxidant enzyme ascorbate peroxidase (APX) in (A) creeping bentgrass 'Penncross' and (B) kentucky bluegrass 'Baron' in response to $21 \mathrm{~d}$ of drought and $35 \mathrm{~d}$ of salinity stress. Bars marked with lowercase letters are for comparison among untreated control, abscisic acid (ABA), and glycine betaine (GB) treatment under well-watered, drought, or salinity conditions. Bars marked with uppercase letter are for comparison among well-watered, drought-stressed, and salinity-stressed plants under untreated control, ABA treatment, and GB treatment. Different letters indicate significant differences based on least significant difference (LSD) test ( $P \leq$ $0.05)$.

in various plant species as discussed in the introduction. In the present study, two grass species exhibited differential responses to GB application. The relative changes in TQ, RWC, and EL responding to GB treatment during drought or salinity stress were greater for kentucky bluegrass than creeping bentgrass. The differential responses between the species became more pronounced after prolonged periods of drought (21 d) or salinity stress $(35 \mathrm{~d})$. Variation resulting from species or specific stressors in response to GB have been previously reported in other studies (Huang et al., 2000). The reasons for differential sensitivity to GB application between the species are unclear. The observed variation in species response could be affected by the abilities of leaves to absorb and retain GB, which governs the extent of osmotic adjustment during drought or salinity stress (Génard et al., 1991; Robinson and Jones, 1986). Alleviation of salinity stress by GB has been associated with a reduction in sodium accumulation and increases in potassium concentrations
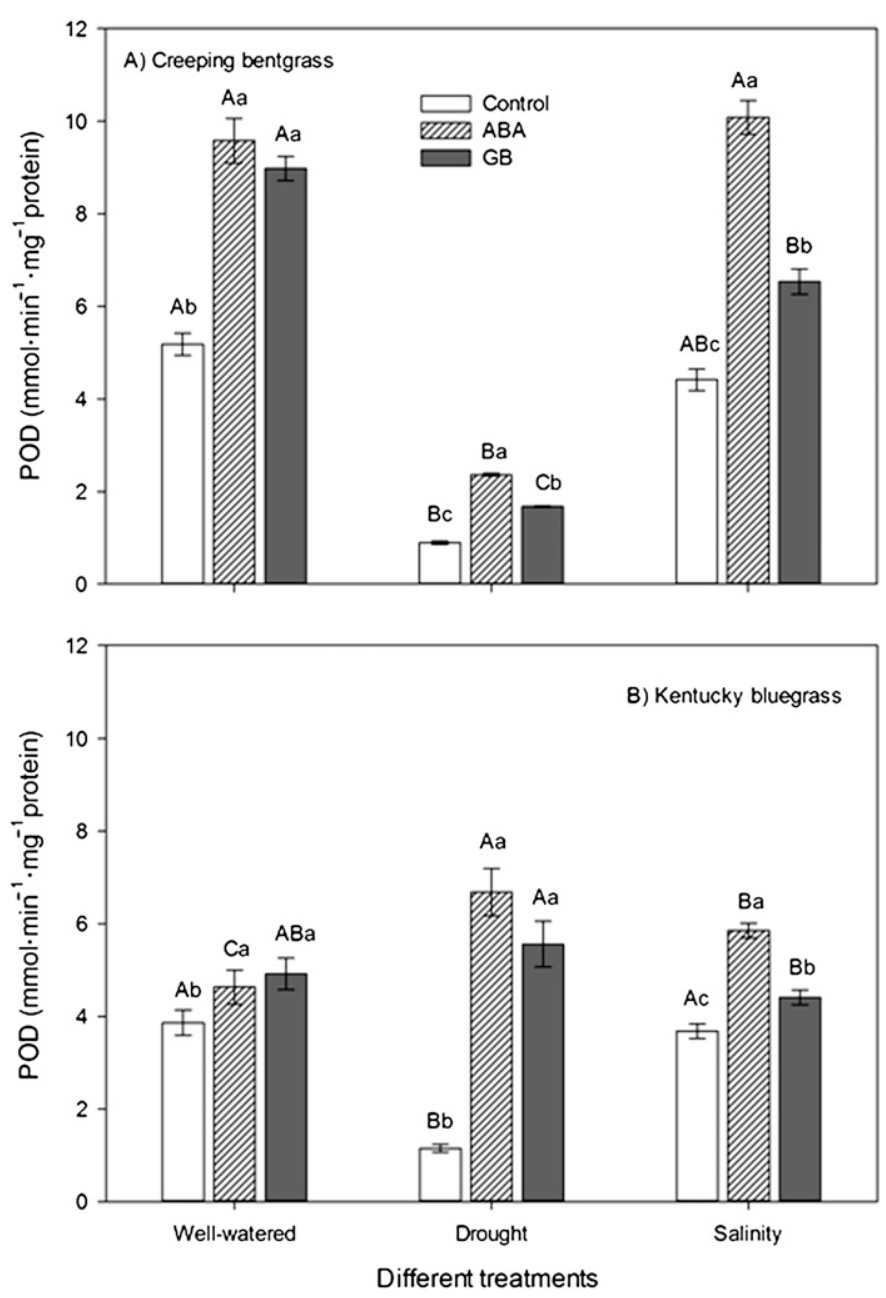

Fig. 12. Activity of the antioxidant enzyme peroxidase (POD) in (A) creeping bentgrass 'Penncross' and (B) kentucky bluegrass 'Baron' in response to $21 \mathrm{~d}$ of drought and $35 \mathrm{~d}$ of salinity stress. Bars marked with lowercase letters are for comparison among untreated control, abscisic acid (ABA), and glycine betaine (GB) treatment under well-watered, drought, or salinity conditions. Bars marked with uppercase letter are for comparison among well-watered, drought-stressed, and salinity-stressed plants under untreated control, ABA treatment, and GB treatment. Different letters indicate significant differences based on least significant difference (LSD) test $(P \leq 0.05)$.

(Lutts, 2000; Rahman et al., 2002). Whether the differential responses to two grass species to GB treatments are associated with differential accumulation of sodium or potassium deserves investigation.

Positive effects of GB in stress responses could also be associated with the protective roles in thylakoid membranes (Ashraf and Foolad, 2007; Génard et al., 1991). Maintenance of cell membrane stability could be attributable in part to the effects of GB application on the antioxidant responses to prevent lipid peroxidation. Lipid peroxidation in cellular membranes is a result of oxidative deterioration of unsaturated lipids and is typically measured by quantifying MDA content (Health and Packer, 1968). In the present study, drought and salinity caused an increase in MDA in untreated control plants for both species. $\mathrm{ABA}$ and GB treatments both reduced MDA content relative to the untreated control treatments under drought or salinity stress in both grass species. The reduction in MDA was greater in kentucky bluegrass than creeping bentgrass. Reduced levels of 
lipid peroxidation after GB application have also been reported in other plant species such as rice (Demiral and Türkan, 2004). Plant antioxidant systems are comprised of a network of multiple enzymes that function to detoxify the various forms of ROS that cause lipid peroxidation. ABA and GB both enhanced the activities of SOD, APX, and POD for both grass species under drought or salinity stress. SOD is a key antioxidant enzyme catalyzing the conversion of highly reactive superoxide to hydrogen peroxide (Zhang and Kirkham, 1996). APX and POD are involved in ROS scavenging to convert hydrogen peroxide into $\mathrm{O}_{2}$ and $\mathrm{H}_{2} \mathrm{O}$ within the gluathione-ascorbate cycle (Cakmak, 1994). Jiang and Zhang (2001) found that maize (Zea mays) seedlings treated with low concentrations of ABA induced antioxidative defense responses by enhancing the activities of SOD, CAT, and APX and the accumulation of antioxidant compounds. Agarwal et al. (2005) also reported suppressed lipid peroxidation through increased activity of SOD, CAT, and APX in wheat treated with low concentrations of ABA. Raza et al. (2007) reported that exogenous application of $100 \mathrm{~mm}$ GB mitigated adverse salinity effects on wheat by increasing activity of SOD, CAT, and POD. Our results in the two perennial grass species along with studies in annual crops strongly support the notion that foliar ABA or GB could be effective in suppressing oxidative damage induced by drought or salinity stress by enhancing antioxidant enzyme activity.

In summary, the results of the present study demonstrated that exogenous application of ABA or GB was effective for improving physiological activities of creeping bentgrass and kentucky bluegrass exposed to drought or salinity stress, but effects were more pronounced for kentucky bluegrass. Both compounds suppressed membrane lipid peroxidation and enhanced antioxidant activity after prolonged periods of drought (21 d) or salinity stress (35 d), although the extent to which ABA and GB treatments did so varied between grass species and stress. Whether suppression of oxidative damage was a result of direct antioxidant effects rather than indirect effects reducing cellular damage is yet to be determined.

\section{Literature Cited}

Agarwal, S., R.K. Sairam, G.C. Srivastava, and R.C. Meena. 2005. Changes in antioxidant enzymes activity and oxidative stress by abscisic acid and salicylic acid in wheat genotypes. Biol. Plant. 49:541-550.

Agboma, P.C., M. Jones, P. Peltonen-Sainio, H. Rita, and E. Pehu. 1997. Exogenous glycinebetaine enhances grain yield of maize, sorghum and wheat grown under two supplementary watering regimes. J. Agron. Crop Sci. 178:29-37.

Ashraf, M. and M.R. Foolad. 2007. Roles of glycine betaine and proline in improving plant abiotic stress resistance. Environ. Exp. Bot. 59:206-216.

Aswath, C.R., S.H. Kim, S.Y. Mo, and D.H. Kim. 2005. Transgenic plants of creeping bent grass harboring the stress inducible gene, 9-cis-epoxycarotenoid dioxygenase, are highly tolerant to drought and $\mathrm{NaCl}$ stress. Plant Growth Regulat. 47:129-139.

Bellaire, B.A., J. Carmody, J. Braud, D.R. Gossett, S.W. Banks, M. Cranlucas, and T.E. Fowler. 2000. Involvement of abscisic aciddependent and -independent pathways in the upregulation of antioxidant enzyme activity during $\mathrm{NaCl}$ stress in cotton callus tissue. Free Radic. Res. 33:531-545.

Blackman, P.G. and W.J. Davies. 1985. Root to shoot communication in maize plants of the effects of soil drying. J. Expt. Bot. 36:39-48.
Blum, A. and A. Ebercon. 1981. Cell membrane stability as a measure of drought and heat tolerance in wheat. Crop Sci. 21:43-47.

Bohnert, H.J. and R.G. Jensen. 1996. Strategies for engineering water stress tolerance in plants. Trends Biotechnol. 14:89-97.

Bradford, M.M. 1976. A rapid and sensitive method for the quantitation of microgram quantities of protein utilizing the principle of protein-dye binding. Anal. Biochem. 72:248-254.

Cakmak, I. 1994. Activity of ascorbate-dependent $\mathrm{H}_{2} \mathrm{O}_{2}$ scavenging enzymes and leaf chlorosis are enhanced in magnesium- and potassium-deficient leaves, but not in phosphorus-deficient leaves. J. Expt. Bot. 45:1259-1266.

Carrow, R.N. and R.R. Duncan. 1998. Salt-affected turfgrass sites: Assessment and management. Wiley, New York, NY.

Demiral, T. and I. Türkan. 2004. Does exogenous glycine betaine affect antioxidative system of rice seedlings under $\mathrm{NaCl}$ treatment? J. Plant Physiol. 161:1089-1100.

Dhindsa, R.S., P. Plumb-Dhindsa, and T.A. Thorpe. 1981. Leaf senescence correlated with increased levels of membrane permeability and lipid peroxidation, and decreased levels of superoxide dismutase and catalase. J. Expt. Bot. 32:93-101.

Fallon, K.M. and R. Phillips. 1989. Responses to water stress in adapted and unadapted carrot cell suspension cultures. J. Expt. Bot. 40:681-687.

Fry, J. and B. Huang. 2004. Applied turfgrass science and physiology. Wiley, Hoboken, NJ.

Gadallah, M.A.A. 1996. Abscisic acid, temperature and salinity interactions on growth and some mineral elements in Carthamus plants. Plant Growth Regulat. 20:225-236.

Génard, H., J. Le Saos, J.-P. Billard, A. Trémolières, and J. Boucaud. 1991. Effect of salinity on lipid composition, glycine betaine content and photosynthetic activity in chloroplasts of Suaeda maritime. Plant Physiol. Biochem. 29:421-427.

Giannopolities, C.N. and S.K. Rise. 1977. Superoxide dismutases. I. Occurrence in higher plants. Plant Physiol. 59:309-314.

Gómez-Cadenas, A., V. Arbona, J. Jacas, E. Primo-Millo, and M. Talon. 2003. Abscisic acid reduces leaf abscission and increases salt tolerance in citrus plants. J. Plant Growth Regul. 21:234-240.

Harinasut, P., K. Tsutsui, T. Takabe, M. Nomura, and S. Kishitani. 1996. Exogenous glycine betaine accumulation and increased salt tolerance in rice seedlings. Biosci. Biotechnol. Biochem. 60:366368 .

Health, R.L. and L. Packer. 1968. Photoperoxiation in isolated chloroplasts. I. Kinetics and stoichiometry of fatty acid peroxidation. Arch. Biochem. Biophys. 125:189-198.

Huang, J., R. Hirji, L. Adam, K.L. Rozwadowski, J.K. Hammerlindl, W.A. Keller, and G. Selvaraj. 2000. Genetic engineering of glycinebetaine production toward enhancing stress tolerance in plants: Metabolic limitations. Plant Physiol. 122:747-756.

Iuchi, S., M. Kobayashi, T. Taji, M. Naramoto, M. Seki, T. Kato, S. Tabata, Y. Kakubari, K. Yamaguchi-Shinozaki, and K. Shinozaki. 2001. Regulation of drought tolerance by gene manipulation of 9-cisepoxycarotenoid dioxygenase, a key enzyme in abscisic acid biosynthesis in Arabidopsis. Plant J. 27:325-333.

Jiang, M. and J. Zhang. 2001. Effect of abscisic acid on active oxygen species, antioxidative defence system and oxidative damage in leaves of maize seedlings. Plant Cell Physiol. 42:1265-1273.

Jiang, Y. and B. Huang. 2001. Drought and heat stress injury to two cool-season turfgrasses in relation to antioxidant metabolism and lipid peroxidation. Crop Sci. 41:436-442.

Lee, S., E.J. Lee, E.J. Yang, J.E. Lee, A.R. Park, W.H. Song, and O.K. Park. 2004. Proteomic identification of annexins, calcium-dependent membrane binding proteins that mediate osmotic stress and abscisic acid signal transduction in arabidopsis. Plant Cell 16:13781391.

Lu, S., W. Su, H. Li, and Z. Guo. 2008. Abscisic acid improves drought tolerance of triploid bermudagrass and involves $\mathrm{H}_{2} \mathrm{O}_{2-}$ and NOinduced antioxidant enzymes activities. Plant Physiol. Biochem. 47:132-138. 
Lutts, S. 2000. Exogenous glycine betaine reduces sodium accumulation in salt-stressed rice plants. Intl. Rice Res. Notes 25:9-40.

Mäkelä, P., R. Munns, T.D. Colmer, A.G. Condon, and P. PeltonenSainio. 1998. Effect of foliar applications of glycine betaine on stomatal conductance, abscisic acid and solute concentrations in leaves of salt- or drought-stressed tomato. Funct. Plant Biol. 25:655663.

Maleki, M., H. Ebrahimzade, M. Gholami, and V. Niknam. 2011. The effect of drought stress and exogenous abscisic acid on growth, protein content and antioxidative enzyme activity in saffron (Crocus sativus L.). Afr. J. Biotechnol. 10:9068-9075.

McCann, S.E. and B. Huang. 2008. Drought responses of kentucky bluegrass and creeping bentgrass as affected by abscisic acid and trinexapac-ethyl. J. Amer. Soc. Hort. Sci. 133:20-26.

McCue, K.F. and A.D. Hanson. 1990. Drought and salt tolerance: Towards understanding and application. Trends Biotechnol. 8:358362.

Mittler, R. 2002. Oxidative stress, antioxidants and stress tolerance. Trends Plant Sci. 7:405-410.

Moons, A., G. Bauw, E. Prinsen, M. Van Montagu, and D. Van Der Straeten. 1995. Molecular and physiological responses to abscisic acid and salts in roots of salt-sensitive and salt-tolerant Indica rice varieties. Plant Physiol. 107:177-186.

Mukherjee, K., A.R. Choudhury, B. Gupta, S. Gupta, and D.N. Sengupta. 2006. An ABRE-binding factor, OSBZ8, is highly expressed in salt tolerant cultivars than in salt sensitive cultivars of indica rice. BMC Plant Biol. 6:18.

Nilsen, E.T. and D.M. Orcutt. 1996. The physiology of plants under stress: Abiotic factors. Wiley, New York, NY.

Pessarakli, M. and I. Szabolcs. 1999. Soil salinity and sodicity as particular plant/crop stress factors, p. 1-16. In: Pessarakli, M. (ed.). Handbook of plant and crop stress. 2nd Ed. Marcel Dekker, New York, NY.

Qin, X. and J.A.D. Zeevaart. 2002. Overexpression of a 9-cisepoxycarotenoid dioxygenase gene in Nicotiana plumbaginifolia increases abscisic acid and phaseic acid levels and enhances drought tolerance. Plant Physiol. 128:544-551.

Rahman, M.S., H. Miyake, and Y. Takeoka. 2002. Effects of exogenous glycine betaine on growth and ultrastructure of saltstressed rice seedlings (Oryza sativa L.). Plant Prod. Sci. 5:33-44.

Rajasekaran, L.R. and T.J. Blake. 1999. New plant growth regulators protect photosynthesis and enhance growth under drought of jack pine seedlings. J. Plant Growth Regul. 18:175-181.

Raza, S.H., H.R. Athar, M. Ashraf, and A. Hameed. 2007. Glycine betaine-induced modulation of antioxidant enzymes activities and ion accumulation in two wheat cultivars differing in salt tolerance. Environ. Exp. Bot. 60:368-376.

Robinson, S.P. and G.P. Jones. 1986. Accumulation of glycinebetaine in chloroplasts provides osmotic adjustment during salt stress. Funct. Plant Biol. 13:659-668.

Serraj, R. and T.R. Sinclair. 2002. Osmolyte accumulation: Can it really help increase crop yield under drought conditions? Plant Cell Environ. 25:333-341.

Skriver, K. and J. Mundy. 1990. Gene expression in response to abscisic acid and osmotic stress. Plant Cell 2:503-512.

Smirnoff, N. and Q.J. Cumbes. 1989. Hydroxyl radical scavenging activity of compatible solutes. Phytochemistry 28:1057-1060.

Topp, G.C., J.L. Davis, and A.P. Annan. 1980. Electromagnetic determination of soil water content: Measurements in coaxial transmission lines. Water Resour. Res. 16:574-582.

Turgeon, A.J. 1996. Turfgrass management. 4th Ed. Prentice-Hall, Upper Saddle River, NJ.

Wang, Z., B. Huang, and Q. Xu. 2003. Effects of abscisic acid on drought responses of kentucky bluegrass. J. Amer. Soc. Hort. Sci. 128:36-41.

Weimberg, R., H.R. Lerner, and A. Poljakoff-Mayber. 1984. Changes in growth and water-soluble solute concentrations in Sorghum bicolor stressed with sodium and potassium salts. Physiol. Plant. $62: 472-480$.

Wilkinson, S. and W.J. Davies. 2010. Drought, ozone, ABA and ethylene: New insights from cell to plant to community. Plant Cell Environ. 33:510-525.

Xiong, Y.C., G.M. Xing, C.M. Gong, F.M. Li, S.M. Wang, Z.X. Li, and Y.F. Wang. 2006. Dual role of abscisic acid on antioxidative defense in grass pea seedling (Lathyrus sativus L.). Pak. J. Bot. 38:999-1014.

Yancey, P.H., M.E. Clark, S.C. Hand, R.D. Bowlus, and G.N. Somero. 1982. Living with water stress: Evolution of osmolyte systems. Science 217:1214-1222.

Yang, W.J., P.J. Rich, J.D. Axtell, K.V. Wood, C.C. Bonham, M.V. Mickelbart, and D. Rhodes. 2003. Genotypic variation for glycine betaine in sorghum. Crop Sci. 43:162-169.

Yang, X. and C. Lu. 2005. Photosynthesis is improved by exogenous glycine betaine in salt-stressed maize plants. Physiol. Plant. 124:343-352.

Zhang, J., W. Jia, J. Yang, and A.M. Ismail. 2006. Role of ABA in integrating plant responses to drought and salt stresses. Field Crops Res. 97:111-119.

Zhang, J. and M.B. Kirkham. 1996. Antioxidant responses to drought in sunflower and sorghum seedlings. New Phytol. 132:361-373. 